Submitted Version of an Accepted Article in the journal Conservation Biology

\title{
Metabolism of aceclofenac in cattle to vulture-killing diclofenac
}

\author{
Galligan, T. H. ${ }^{1}$, Taggart, M. A. ${ }^{2}$, Cuthbert, R. J. ${ }^{1,3}$, Svobodova, D. ${ }^{2}$, Chipangura, J. ${ }^{4}$, \\ Alderson, D. ${ }^{5}$, Prakash, V.M..$^{6}$ Naidoo, V. ${ }^{3}$
}

1. RSPB Centre for Conservation Science, The Lodge, Sandy, Bedfordshire, SG19 2DL, UK

2. Environmental Research Institute, University of the Highlands and Islands, Castle Street, Thurso, Scotland, KW14 7JD, UK

3. Wildlife Conservation Society, P.O. Box 277, Goroka, Eastern Highlands Province 441, Papua New Guinea

4. Department of Paraclinical Sciences, Faculty of Veterinary Science, University of Pretoria, Onderstepoort, Gauteng, 0110, South Africa

5. SAC Consulting Veterinary Services, Janetstown, Thurso, Scotland, KW14 7XF, UK

6. Bombay Natural History Society, Hornbill House, Mumbai, 400023, India

Corresponding author: Toby H. Galligan ${ }^{1}$ toby.galligan@ rspb.org.uk 


\begin{abstract}
The non-steroidal anti-inflammatory drug (NSAID) diclofenac is highly toxic to Gyps vultures and its recent widespread use in South Asia caused catastrophic declines in at least three scavenging raptors. The manufacture of veterinary formulations of diclofenac has since been banned across the region with mixed success. However, at least 12 other NSAIDs are available for veterinary use in South Asia. Aceclofenac is one of these compounds and it is known to metabolise into diclofenac in some mammal species. The metabolic pathway of aceclofenac in cattle, the primary food of vultures in South Asia, is unknown. In this study, we give six cattle the recommended dose of aceclofenac $(2 \mathrm{mg} / \mathrm{kg})$, collect blood along a time series and undertake a pharmacokinetic analysis of aceclofenac and diclofenac-metabolites in their plasma using liquid chromatography with mass spectrometry. We found that nearly all of the aceclofenac administered to the cattle was very rapidly metabolised into diclofenac. Therefore, treating livestock with pure diclofenac or aceclofenac poses the same risk to vultures. This fact, coupled with the risk that aceclofenac may replace diclofenac in the veterinary market, fortifies the need for an immediate ban on all aceclofenac formulations that can be used to treat livestock. Without such a ban, the recovery of vultures across South Asia will not be successful.
\end{abstract}

Keywords: Gyps; ecotoxicology; pharmacokinetics; NSAID; non-steroidal anti-inflammatory drugs; vulture declines; threats to vultures; pharmaceuticals in the environment 


\section{Introduction}

The non-steroidal anti-inflammatory drug (NSAID) diclofenac is highly toxic to Gyps vultures (Oaks et al. 2004; Swan et al. 2006a). Widespread use of diclofenac in South Asia to treat livestock - the primary food source - during the 1990s and 2000s caused catastrophic declines in three resident Gyps species (Green et al. 2004, 2007; Prakash et al. 2012) and possibly other birds of prey (e.g. Galligan et al. 2014; Sharma et al. 2014; Paudel et al. 2015) that scavenged on the carcasses of recently treated livestock. The mechanisms of toxicity in Gyps vultures remains unknown (but see Hutchinson et al. 2014); however, individuals exposed to even low concentrations of diclofenac in the carcasses of animals treated just before death suffer fatal necrosis of the kidneys (Oaks et al. 2004; Swan et al. 2006).

Beginning in 2006, the governments of India, Pakistan, Nepal and Bangladesh banned the veterinary use of diclofenac to conserve the now critically endangered resident Gyps vultures (IUCN Red List 2015). However, these bans have not brought about a complete cessation to diclofenac use (Cuthbert et al. 2011, 2014). Compounding this problem, at least another twelve NSAIDs are available for veterinary use across the Indian sub-continent (Cuthbert et al. 2011; SAVE unpublished data). Among these, experimental safety-testing has shown that one is vulture-toxic (ketoprofen: Naidoo et al. 2010a, b) and another is vulture-safe (meloxicam: Swan et al 2006b; Swarup et al. 2007). Two more are almost certainly toxic given that elevated residues of these drugs have been found in dead vultures with clinical signs of NSAID poisoning (flunixin: Zorilla et al. 2014; nimesulide: Cuthbert et al. 2015).

Sharma (2012) suggested that a fifth NSAID, aceclofenac, was likely to be toxic to vultures, given its 1) close structural and pharmacological resemblance to diclofenac (Fig. 1); and 2) evidence that diclofenac was a metabolite of aceclofenac in humans and other non- 
ruminant mammals (e.g. Bort et al. 1999; Hinz et al. 2003). Aceclofenac is a phenylacetic acid derived NSAID. Like many NSAIDs, the analgesic, anti-arthritic and anti-pyretic properties of aceclofenac are used to treat a wide variety of common ailments in livestock in South Asia. Sharma (2012) concluded that aceclofenac was either likely to be toxic to vultures independently or as a result of its conversation into diclofenac within ruminants which make up the bulk of food for vultures in South Asia.

In this study, we test this latter hypothesis by examining the plasma pharmacokinetics of aceclofenac and its potential diclofenac-metabolites in Bos taurus cattle. We then compare our results to existing pharmacokinetic data for diclofenac and comment on the risk posed to vultures by increasing veterinary use of aceclofenac in South Asia. 


\section{Methods}

Research and animal ethics approval for this study were given by the Research Committee of the Faculty of Veterinary Science, University of Pretoria, and the Animal Ethics Committee, University of Pretoria, respectively.

Most aceclofenac products available in South Asia are oral bolus formulations. We purchased a bolus product in Bhopal, Madhya Pradesh, branded as NBE PLUS, manufactured by Hanuchem Laboratories, Solan, Himachal Pradesh (under licence number: MNB/05/261). Each bolus contained $300 \mathrm{mg}$ of aceclofenac and $1500 \mathrm{mg}$ of paracetamol.

We conducted a closed single dose pharmacokinetic study on six healthy female Bos taurus cattle (Friesian) aged >12 months. Cattle were sourced from a single commercial livestock-owner in Pretoria, South Africa. To ensure that the animals were free of any NSAIDs prior to exposure to aceclofenac, the animals were kept under non-treatment quarantine in outdoor camps of the University of Pretoria for six weeks prior to acclimatisation.

One-week prior to exposure, the cattle were moved into the controlled stables where they were housed in pairs in climate controlled stables on straw bedding at night. Food, water and exercise were provided daily. During the acclimatisation period each animal received a complete veterinary examination and was deemed fit and healthy. Throughout the study, the cattle were observed by a veterinarian or animal technician for signs of adverse drug reactions, but none were detected. After the study, each animal was returned to its owner with an enforced three month withdrawal period.

On the first day of the study, each animal was weighed (mean $\pm \mathrm{SD}=323 \pm 93 \mathrm{~kg}$ ). A 10 ml sample of blood was collected from each animal's jugular vein into an evacuated heparinised tube. Next, all animals were given the aceclofenac bolus (individualised to the animal's weight) 
orally into the back of the mouth by hand and monitored to ensure that the bolus was swallowed. The recommended single dose for cattle in India was used; this equated to approximately 2,000 $\mu \mathrm{g}$ of aceclofenac per $\mathrm{kg}$ of cattle body weight. The numbers of bolus given per animal were recorded for subsequent dose equalisation of the pharmacokinetic data. Subsequent samples of blood $(10 \mathrm{ml})$ were then collected at eleven time points post administration: $0.25,0.50,0.75$, 1.00, 1.50, 2.00, 3.00, 5.00, 7.00, 9.00 and $12.00 \mathrm{~h}$. Within $2 \mathrm{~h}$ of collection, all blood samples were centrifuged at $\sim 3,000 \mathrm{~g}$ for $15 \mathrm{~min}$ and the supernatant (plasma) was transferred to a glass screw-top vial and immediately frozen at $-80^{\circ} \mathrm{C}$.

Plasma samples were couriered on dry ice to the UK. A subsample of each $(0.3 \mathrm{ml})$ was extracted by: vortex mixing with $2.5 \mathrm{ml}$ of HPLC grade acetonitrile for $20 \mathrm{~s}$; setting to stand at room temperature for 10 minutes; vortex mixing for a further $20 \mathrm{~s}$; and centrifuging at $2000 \mathrm{rpm}$ $(671 \mathrm{~g})$ for $10 \mathrm{~min}$. The supernatant was syringe filtered $(0.2 \mu \mathrm{m}$ HDPE disposable) directly into an amber $2 \mathrm{ml}$ screw top LC vial. These extracts were held at $-20^{\circ} \mathrm{C}$ until analysis. NSAID and metabolite concentrations were determined using a liquid chromatography electrospray ionisation triple quadrupole mass spectrometry system (LC-ESI-MS/MS) utilising a methodology adapted after Taggart et al. (2009). Target analytes determined in negative ion mode were aceclofenac (target mass $\mathrm{m} / \mathrm{z} 352$ ) and the suspected metabolites "diclofenacmetabolite" (masses 294 $\rightarrow 250$ ) and "4'-OH-diclofenac-metabolite" (masses 310 $\rightarrow$ 266; see also Support Information). Mean recovery of these compounds spiked into blank plasma at three different concentration levels and extracted as above was $>90 \%(n=12)$ for all three compounds. See Support Information for further detail of the analyses.

We used Kinetica 5.1 (Thermo, 2012) to perform non-compartmental modelling for aceclofenac, the diclofenac-metabolite and the 4'-OH-diclofenac-metabolite per animal. We 
calculated the following parameters from a non-compartmental model: the maximum plasma level $\left(\mathrm{C}_{\max }\right)$ and the time to reach it $\left(\mathrm{t}_{\max }\right)$ read directly from the plasma concentration versus time curve; the elimination constant $(\lambda)$ using least squares linear regression from the concentrations on the natural logarithmic scale attained for the last three time points for all animals; the area under the plasma concentration versus time curve $\left(\mathrm{AUC}_{\text {last }}\right)$ at the last measured concentration $\left(\mathrm{C}_{\text {last }}\right)$ calculated according to the linear trapezoidal rule $\left(\mathrm{AUC}_{\text {last }}=\left(\mathrm{t}_{\text {last }}-\mathrm{t}_{\text {last- }}\right.\right.$ 1) $\left.*\left[\mathrm{C}_{\text {last }}+\mathrm{C}_{\text {last }-1}\right] / 2\right)$; the area under the moment curve $\left(\mathrm{AUMC}\right.$ last $=\left(\mathrm{t}_{\text {last }}-\mathrm{t}_{\text {last }-1}\right) *\left[\mathrm{t}_{\text {last }} * \mathrm{C}_{\text {last }}+\mathrm{t}_{\text {last }}\right.$ $\left.\left.1^{*} \mathrm{C}_{\text {last-1 }}\right] / 2\right)$ used to calculate the mean residence time $\left(\mathrm{MRT}=\mathrm{AUCM}_{\mathrm{inf}} / \mathrm{AUC}_{\mathrm{inf}}\right)$; the extrapolated concentration for each chemical to infinity $\left(\mathrm{AUC}_{\mathrm{inf}}=\mathrm{AUC}_{\text {last }}+\mathrm{C}_{\text {last }} / \lambda\right)$; and the terminal half-life was calculated as $\ln (2) / \lambda$. All parameters are presented as geometric means with standard deviations; and all comparisons are presented as the difference between geometric means with $95 \%$ confidence intervals. 


\section{Results}

We detected the diclofenac-metabolite at the very first sampling time point $(0.25 \mathrm{~h})$ and at every subsequent time point measured (Fig. 2b). The plasma concentration of diclofenac-metabolite was $24-62 \%$ less than that of aceclofenac before $2 \mathrm{~h}$ (Fig. 2, 3). At $2 \mathrm{~h}$, each chemical was equivalent (aceclofenac versus diclofenac-metabolite: 0.50 vs. 0.49; Fig. 2, 3). After 2 h, the plasma concentration of diclofenac-metabolite was $21-117 \%$ greater than that of aceclofenac (Fig. 2, 3). 4'-OH-diclofenac was a minor metabolite in the first $12 \mathrm{~h}$ (Fig. 3).

Pharmacokinetic parameters were similar among cattle (Supporting Information). Diclofenac-metabolite had a mean $\mathrm{C}_{\max }$ that was $61 \%$ greater than and $5 \mathrm{~h}$ later than that of aceclofenac (Table 1); however, the difference in mean $\mathrm{C}_{\max }$ was not statistically significant (geometric mean difference $[ \pm 95 \% \mathrm{CI}]=0.71[0.31,1.45] \mu \mathrm{g} / \mathrm{ml})$. The mean area under the curve for diclofenac-metabolite was between 120 and $1163 \%$ greater than that of aceclofenac (Table 1), depending on how it was calculated, and statistically significant in all cases (AUC last: $9.52[5.77,15.72] \mu \mathrm{g} . \mathrm{h} / \mathrm{ml} ; \mathrm{AUMC}_{\text {last: }} 77.98$ [47.93, 126.47] $\mu \mathrm{g} . \mathrm{h}^{2} / \mathrm{ml} ; \mathrm{AUC}_{\mathrm{inf}}: 27.66$ [21.87, 33.73] $\mu \mathrm{g} . \mathrm{h} / \mathrm{ml}$ ). Diclofenac-metabolite had a mean $\mathrm{t}^{\mathrm{t}} / 2$ and mean MRT that were both $44 \%$ longer than that of aceclofenac (Table 1); however, the difference in mean $t^{1 / 2}$ was not significant $(1.86[0.86,3.46] \mathrm{h})$, whereas the difference in mean MRT was significant $(2.68[1.24,4.99] \mathrm{h})$. 


\section{Discussion}

Our study confirms the hypothesis (proposed by Sharma, 2014) that aceclofenac is metabolised into diclofenac within cattle. Two hours after administration of aceclofenac, cattle had as much diclofenac-metabolite circulating in their blood as the pure drug, indicating a very rapid conversion of the aceclofenac into diclofenac. At all subsequent time points tested here, cattle had far higher plasma concentrations of diclofenac than aceclofenac. Therefore, aceclofenac is pro-drug of diclofenac. It follows, that the use of aceclofenac to treat livestock in South Asia is just as dangerous to Critically Endangered Gyps vultures as the use of pure diclofenac to do the same.

Our estimate of total exposure of diclofenac-metabolite $\left(A U C_{i n f}=48 \mu \mathrm{g}^{*} \mathrm{~h} / \mathrm{mL}\right)$ is equivalent to that of pure diclofenac in cattle in two previous studies scaled to a $2 \mathrm{mg} / \mathrm{kg}$ dose specifically, EMEA (2003) AUC $=(70 / 2.5) * 2=56 \mu \mathrm{g} * \mathrm{~h} / \mathrm{mL}$ and Mestrino et al. (2006) AUC ${ }_{\text {inf }}$ $=10 * 4=40 \mu \mathrm{g} * \mathrm{~h} / \mathrm{mL}$. These are the only studies we know of where the total exposure of diclofenac has been shown. Both delivered diclofenac intramuscularly; however, it is important to note that the methods for calculating AUC differed between all three studies, as such, estimates may be expected to differ slightly.

One potential concern with data obtained in this study was a concentration curve that only extended up to 12 hours. As a result, the ratio of $\mathrm{AUC}_{\mathrm{inf}}: \mathrm{AUC}_{\text {last }}$ for the diclofenac metabolite was $62 \%$, and potentially inaccurate. Nonetheless, we believe that $\mathrm{AUC}_{\text {inf }}$ calculated here is an accurate representation of the total exposure of cattle to diclofenac-metabolite following treatment with aceclofenac as sufficient time points were present to estimate the elimination constant for the diclofenac-metabolite, while its terminal half-life (i.e., $6.09 \pm 3.47 \mathrm{~h}$ ) was similar to the reported half-life (i.e., 5.9 hours) reported by the European Medicines Agency 
(EMEA 2003). With AUC being an indicator of the extent of exposure after drug administration or, in this case, the extent of pro-drug conversion, we estimate that the conversion of $2 \mathrm{mg} / \mathrm{kg}$ of aceclofenac could result in a similar or higher extent of exposure as for $1 \mathrm{mg} / \mathrm{kg}$ diclofenac as a pure active pharmaceutical ingredient. With the clinical use of diclofenac and aceclofenac in India being $1 \mathrm{mg} / \mathrm{kg}$ and $2 \mathrm{mg} / \mathrm{kg}$, respectively, we conclude that the use of aceclofenac in cattle is no different to use of pure diclofenac at their respectively indicated dose.

Kinetic homogeneity - that is, the theory that observed concentrations of chemicals in plasma are proportional to those expected in tissues - makes analysis of diclofenac-metabolite in cattle tissue redundant. It can be assumed that all tissues in a cow treated with aceclofenac would absorb and eliminate diclofenac as a metabolite at rates relative to those we report for plasma. It follows that a proportion of vultures feeding on the carcass of a cow given aceclofenac would be poisoned by diclofenac. A residue depletion study of $14 \mathrm{C}$-diclofenac administered $(2.5 \mathrm{mg} / \mathrm{kg}$ bw/day; 3 days; intramuscularly) to 16 calves, subsequently slaughtered at 3, 7, 14 and 17 days post-administration, showed concentrations of $150-1040 \mu \mathrm{g} / \mathrm{kg}$ for liver (peak at 7 days), 117$324 \mu \mathrm{g} / \mathrm{kg}$ for kidney (peak at 3 days), 234-6363 $\mu \mathrm{g} / \mathrm{kg}$ for muscle at the injection site (peak at 3 days) and 0-14 $\mu \mathrm{g} / \mathrm{kg}$ for muscle away from the injection site (peak at 3 days; EMEA 2003). As expected, these concentrations are lower and the periods of absorption and elimination longer than what we found for diclofenac-metabolite in plasma. Diclofenac as a metabolite is eliminated in cattle similarly to pure diclofenac, the proportion poisoned would also be similar to the proportion poisoned at a carcass of a cow recently treated with pure diclofenac (>10\%: Green $e t$ al. 2006), if the mean time between dosing and death is the same for both drugs.

The illegal use of human formulations of diclofenac in livestock remains the greatest threat to Gyps vultures in South Asia (Cuthbert et al. 2011). A recent strengthening of the ban on 
diclofenac to include human formulations in vials larger than $3 \mathrm{ml}$ is hoped to make dosing large animals less convenient and more expensive and thereby all but end the use of the vulture-killing drug in livestock. However, it may also elicit an increase in the use of aceclofenac, particularly if pharmaceutical companies seek to promote this drug as an analogue of diclofenac. This risk fortifies the need for an immediate ban on all aceclofenac formulations that can be used to treat livestock. Since aceclofenac is also used in human health care, such a ban must cover the manufacture, distribution, retail and use of bolus and injectable formulations in doses suitable for large animals (i.e., vials $>3 \mathrm{ml}$ ) and not just formulations labelled for veterinary use. Without such a ban, the recovery of Critically Endangered vultures across the Indian sub-continent will not be successful.

Acknowledgements We thank two anonymous reviewers for their comments on our original manuscript and Rohan Shringarpure for acquiring the aceclofenac used in this study. This study was largely funded by the RSPB Centre for Conversation Science. In addition, SAC Consulting: Veterinary Services receives funding from the Scottish Government through the Veterinary and Advisory Services (VAS) programme.

\section{Supporting information}

Pharmacokinetic parameters obtained from non-compartmental modelling for aceclofenac and diclofenac-metabolite in six cattle (Appendix S1). LC-ESI-MS/MS ion count trace for the analysis of a mixed calibration standard containing the three target compounds of interest (Appendix S2). 


\section{Literature cited}

Bort, R., et al. 1996. Comparative metabolism of the non-steroidal anti-inflammatory drug, aceclofenac, in the rat, monkey, and human. Drug Metabolism and Disposition 24:969-975.

Cuthbert, R.J., et al. 2011. Assessing the ongoing threat from veterinary NSAIDs to Critically Endangered Gyps vultures in India. Oryx 45:420-426.

Cuthbert, R.J., et al. 2014. Avian scavengers and the threat from veterinary pharmaceuticals. Philosophical Transactions of the Royal Society B 369:20130574.

Cuthbert, R.J., et al. 2015. Continuing mortality of vultures in India associated with illegal veterinary use of diclofenac and a potential threat from nimesulide. Oryx 50: 104-112.

EMEA 2003 Diclofenac summary report. EMEA/MRL/885/03-Final (September 2003).

Galligan, T.H., et al. 2014. Have population declines in Egyptian vulture and red-headed vulture in India slowed since the 2006 ban on veterinary diclofenac? Bird Conservation International 24:272-281.

Green, R.E., et al. 2004. Diclofenac poisoning as a cause of vulture population declines across the Indian subcontinent. Journal of Applied Ecology 41:793-800.

Green, R.E., et al. 2006. Collapse of Asian vulture populations: risk of mortality from residues of the veterinary drug diclofenac in carcasses of treated cattle. Journal of Applied Ecology 43:949956.

Green, R.E., et al. 2007. Rate of decline of the oriental white-backed vulture population in India estimated from a survey of diclofenac residues in carcasses of ungulates. PLoS ONE 2:e686. 
Hinz, B., et al. 2003. Simultaneous determination of aceclofenac and three of its metabolites in human plasma by high-performance liquid chromatography. Biomedical Chromatography 17:268-275.

Hutchinson, T. H., et al. Comparative metabolism as a key driver of wildlife species sensitivity to human and veterinary pharmaceuticals. Philosophical Transactions of the Royal Society B 369: 20130583.

IUCN (International Union for Conservation of Nature). 2014. The IUCN red list of threatened species. Available from www.iucnredlist.org (accessed October 2015).

Kinetica 5.0. Thermo Fisher Scientific Inc. 2005-2008.

Naidoo, V., et al. 2010a. The toxicokinetics of ketoprofen in Gyps coprotheres: toxicity due to zero-order metabolism. Archives of Toxicology. 84:761-766.

Naidoo, V. et al. 2010b. Toxicity of NSAIDs to Gyps vultures: a new threat from ketoprofen. Biology Letters 6:339-341.

Oaks, J.L. et al. 2004. Diclofenac residues as the cause of vulture population decline in Pakistan. Nature 427:630-633.

Paudel, K., et al. 2015. Population trends in Himalayan griffon in Upper Mustang, Nepal, before and after the ban on diclofenac. Bird Conservation International in press.

Prakash, V., et al. 2012. The population decline of Gyps vultures in India and Nepal has slowed since the veterinary use of diclofenac was banned. PLoS ONE 7:e49118.

Sharma, P. 2012. Aceclofenac as a potential threat to Critically Endangered vultures in India: a review. Journal of Raptor Research 46:314-318. 
Sharma, A.K., et al. 2014. Diclofenac is toxic to the Steppe Eagle Aquila nipalensis: widening the diversity of raptors threatened by NSAID misuse in South Asia. Bird Conservation International 24:282-286.

Swan, G.E., et al. 2006a. Toxicity of diclofenac to Gyps vultures. Biological Letters 2:279-282.

Swan, G.E., et al. 2006b. Removing the threat of diclofenac to Critically Endangered Asian Vultures. PLoS Biology 4:e66.

Swarup, D., et al. 2007. The safety of meloxicam to Critically Endangered Gyps vultures and other scavenging birds in India. Animal Conservation 10:192-198.

Taggart, M.A., et al. 2009. Analysis of nine NSAIDs in ungulate tissues available to Critically Endangered vultures in India. Environmental Science Technology 43:4561-4566.

Zorrilla, I., et al. 2015. Suspected flunixin poisoning of a wild Eurasian griffon vulture from Spain. Conservation Biology 29:587-566. 
Table 1. Pharmacokinetic parameters obtained from non-compartmental modelling for aceclofenac and diclofenac-metabolite in six Bos taurus cattle. Values are geometric means with standard deviations.

\begin{tabular}{|c|c|c|c|}
\hline & & Aceclofenac & Diclofenac-metabolite \\
\hline Parameters & Units & Mean \pm SD & Mean \pm SD \\
\hline $\mathrm{C}_{\max }$ & $\mu \mathrm{g} / \mathrm{mL}$ & $1.16 \pm 0.51$ & $1.87 \pm 1.08$ \\
\hline $\mathrm{T}_{\max }$ & $\mathrm{h}$ & $1.57 \pm 0.75$ & $6.26 \pm 1.03$ \\
\hline $\mathrm{AUC}_{\text {last }}$ & $\mu \mathrm{g} * \mathrm{~h} / \mathrm{mL}$ & $7.88 \pm 4.12$ & $17.40 \pm 9.78$ \\
\hline $\mathrm{AUC}_{\mathrm{inf}}$ & $\mu \mathrm{g} * \mathrm{~h} / \mathrm{mL}$ & $10.51 \pm 5.96$ & $48.34 \pm 17.70$ \\
\hline$\lambda$ & $1 / \mathrm{h}$ & $0.16 \pm 0.05$ & $0.11 \pm 0.05$ \\
\hline $\mathrm{AUMC}_{\text {last }}$ & $\mu \mathrm{g} * \mathrm{~h}^{2} / \mathrm{mL}$ & $39.03 \pm 22.55$ & $117.01 \pm 68.91$ \\
\hline$t^{1} / 2$ & $\mathrm{~h}$ & $4.23 \pm 1.26$ & $6.09 \pm 3.47$ \\
\hline MRT & $\mathrm{h}$ & $6.10 \pm 1.81$ & $8.78 \pm 5.01$ \\
\hline
\end{tabular}


Figure 1. Chemical structure of pure aceclofenac and its likely primary metabolites in mammals, diclofenac and 4 'hydroxydiclofenac.

Figure 2. Plasma concentration $(\mu g / m L)$ over time $(h)$ for $(a)$ aceclofenac and $(b)$ diclofenacmetabolite of aceclofenac in six female Bos taurus cattle.

Figure 3. Additive geometric mean plasma concentration $(\mu \mathrm{g} / \mathrm{mL})$ over time $(h)$ for aceclofenac (dark grey), diclofenac-metabolite of aceclofenac (light grey) and 4'hydroxydiclofenacmetabolite of aceclofenac (black) in six female Bos taurus cattle. 


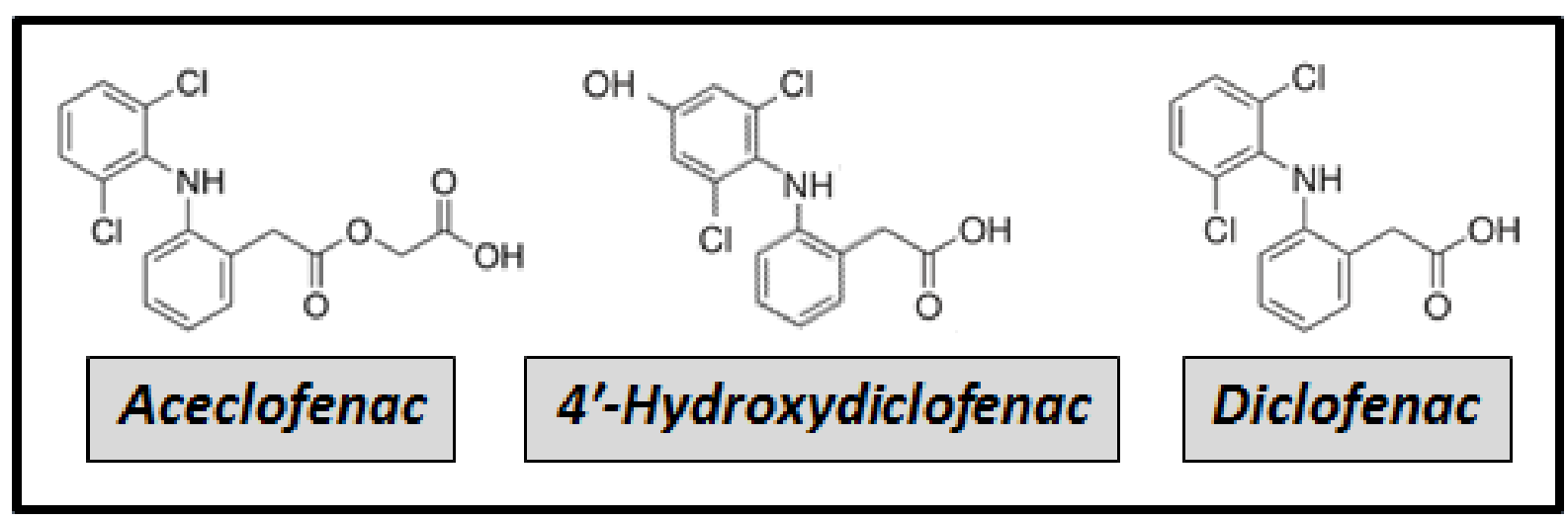

Page 17 of 22 
Fig. 2
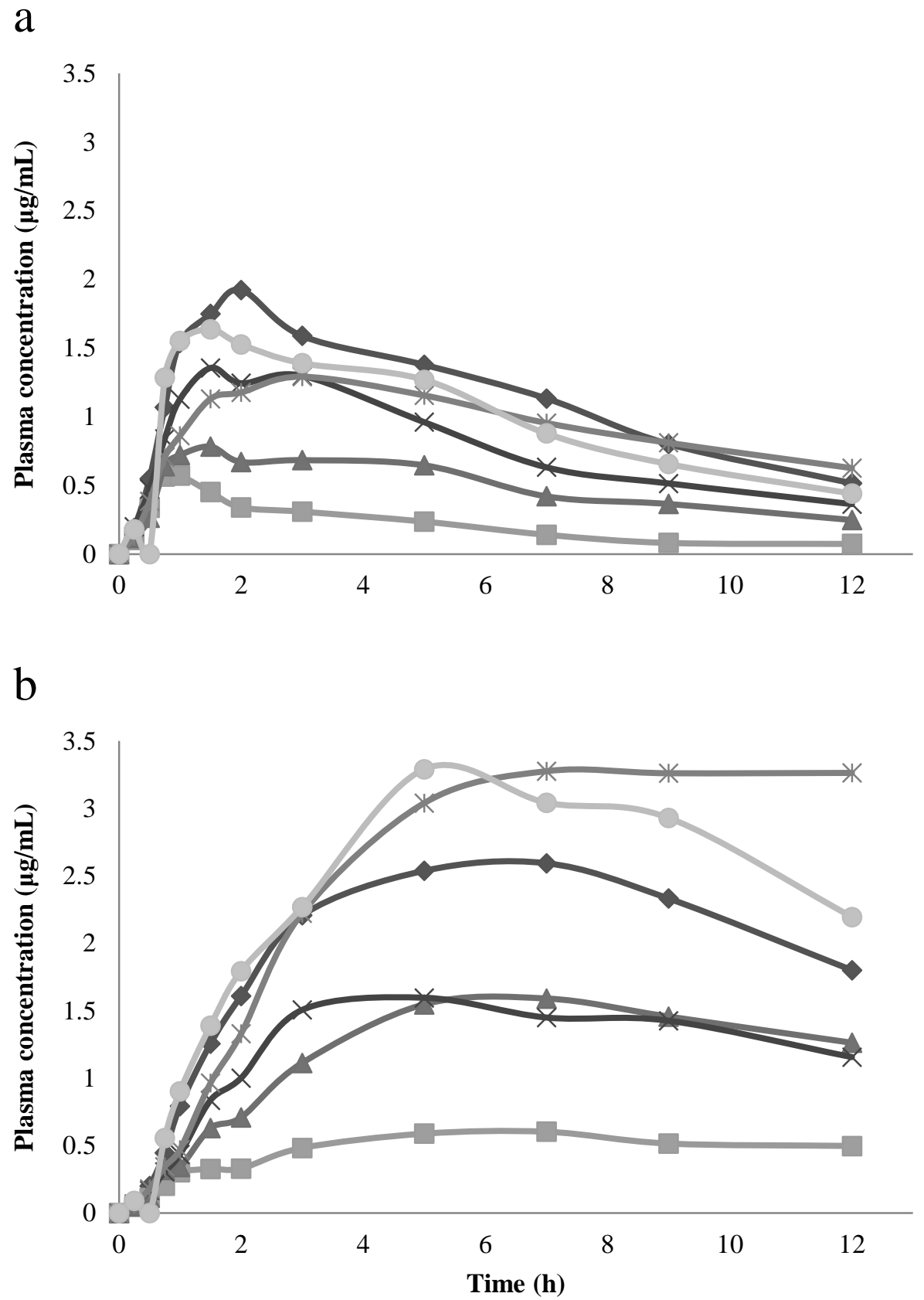

Page 18 of 22 
Fig. 3

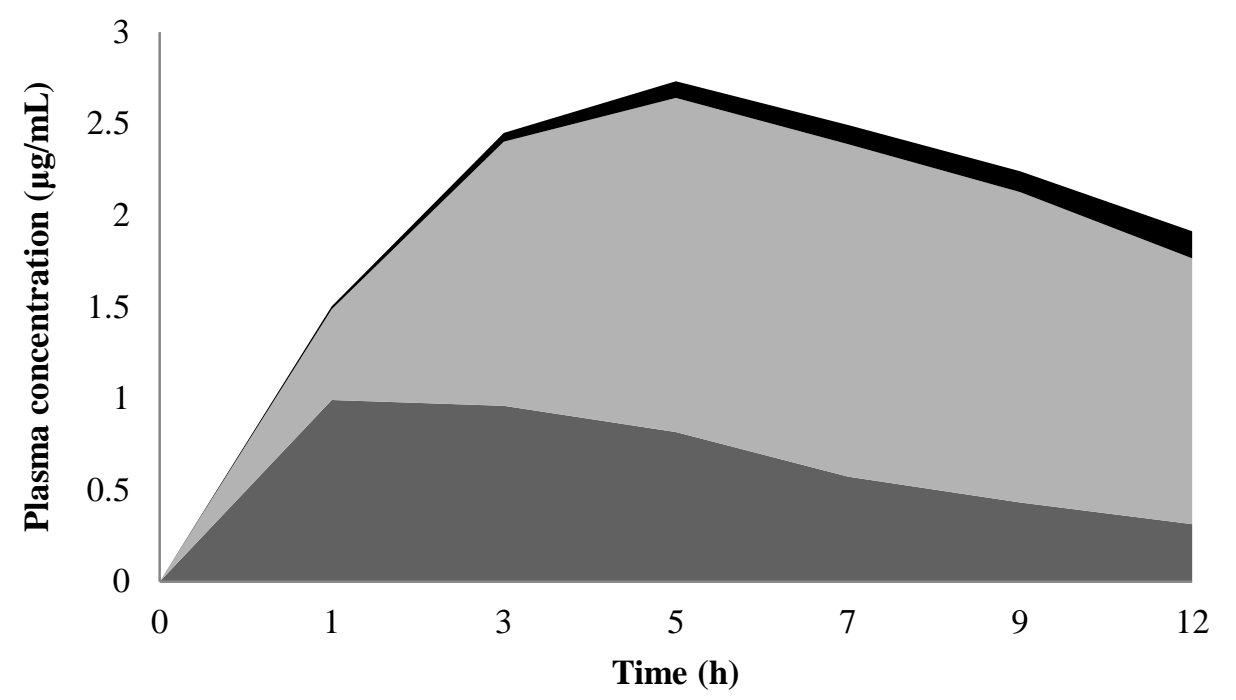

Page 19 of 22 
Appendix S1 Pharmacokinetic parameters obtained from non-compartmental modelling for aceclofenac and diclofenac-metabolite in six cattle.

Animal $\quad \mathrm{C}_{\max } \quad \mathrm{T}_{\max } \quad \mathrm{AUC}_{\text {last }} \quad \mathrm{AUC}_{\mathrm{inf}} \quad \lambda \quad \mathrm{AUMC}_{\text {last }} \quad \mathrm{t}^{1} \mathbf{2} \quad \mathrm{MRT}^{2}$

$\begin{array}{lllllllllll}\text { Units } & \mu \mathrm{g} / \mathrm{mL} & \mathrm{h} & \mu \mathrm{g} * \mathrm{~h} / \mathrm{mL} & \mu \mathrm{g} * \mathrm{~h} / \mathrm{mL} & 1 / \mathrm{h} & \mu \mathrm{g}^{*} \mathrm{~h}^{2} / \mathrm{mL} & \mathrm{h} & \mathrm{h}\end{array}$

Aceclofenac

$\begin{array}{rrrrrrrrr}1 & 1.92 & 2.00 & 13.53 & 3.34 & 0.16 & 69.19 & 4.23 & 6.11 \\ 2 & 0.57 & 0.75 & 2.48 & 0.29 & 0.25 & 10.03 & 2.82 & 4.07 \\ 3 & 0.78 & 1.50 & 5.85 & 2.41 & 0.13 & 30.06 & 5.28 & 7.62 \\ 4 & 1.36 & 1.50 & 9.36 & 3.22 & 0.19 & 45.76 & 3.63 & 5.24 \\ 5 & 1.29 & 3.00 & 11.20 & 7.67 & 0.11 & 63.40 & 6.34 & 9.15 \\ 6 & 1.64 & 1.50 & 11.61 & 3.17 & 0.18 & 58.40 & 3.92 & 5.66\end{array}$

Diclofenac-metabolite

$\begin{array}{rrrrrrrrr}1 & 2.59 & 7.00 & 24.42 & 24.64 & 0.15 & 160.20 & 4.52 & 6.52 \\ 2 & 0.60 & 7.00 & 5.74 & 17.57 & 0.05 & 37.84 & 13.04 & 18.81 \\ 3 & 1.59 & 7.00 & 14.58 & 40.58 & 0.12 & 100.03 & 5.65 & 8.16 \\ 4 & 1.59 & 5.00 & 15.07 & 26.65 & 0.18 & 97.97 & 3.77 & 5.43 \\ 5 & 3.28 & 7.00 & 30.81 & 38.81 & 0.08 & 221.32 & 8.25 & 11.90 \\ 6 & 3.29 & 5.00 & 29.21 & 40.43 & 0.14 & 195.20 & 4.91 & 7.08\end{array}$




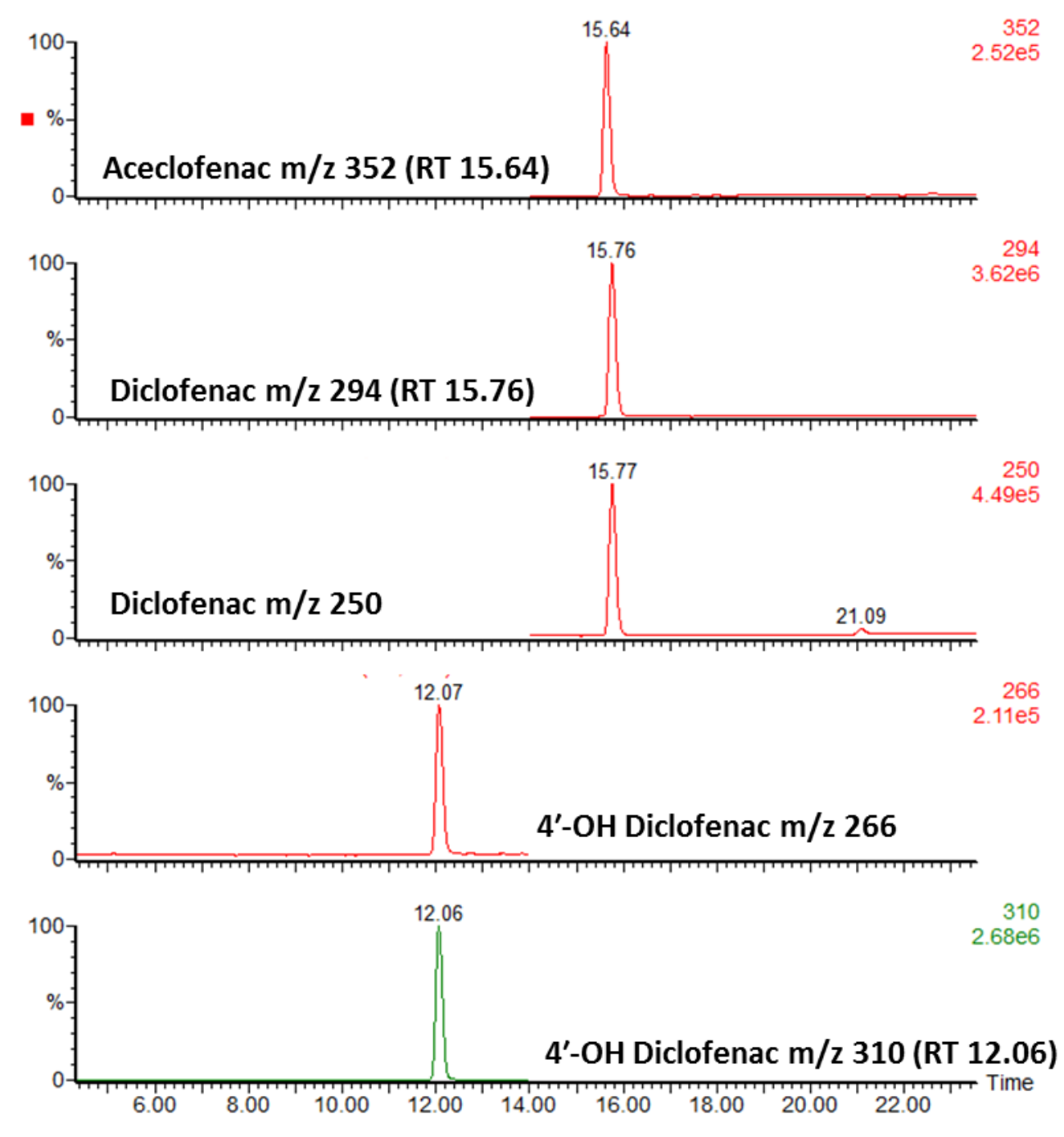

Appendix S2 LC-ESI-MS/MS ion count trace for the analysis of a mixed calibration standard containing the 3 target compounds of interest - aceclofenac, diclofenac and 4-OH diclofenac. Total run time 30 minutes. Masses m/z 266 and 310 are monitored up to 14 minutes, masses 352 , 294 and 250 are monitored beyond 14 minutes. Although not large, sufficient retention time separation between aceclofenac and diclofenac is observed (at 15.64 vs. 15.76). The limit of quantification (LOQ) for aceclofenac, diclofenac and 4-OH diclofenac was 17.4, 5.5 and 2.8 
$\mathrm{ng} / \mathrm{ml}$, respectively. The intra-run (48 hour run; $\mathrm{n}=8$ ) coefficient of variation at the $100 \mathrm{ng} / \mathrm{ml}$ level was 4.5, 2.4 and 5.4\% for aceclofenac, diclofenac and 4-OH diclofenac, respectively. 